\section{Cerebellar Degeneration in Association with Carcinoma of the Stomach}

Brit. med.F., 1968, 1, 34

Subacute cortical cerebellar degeneration is being recognized with increasing frequency in relation to various types of carcinoma. Croft and Wilkinson (1965) pointed out that " as more examples of neuromyopathy are seen, it becomes apparent that any type of neuromyopathy may occur with any type of malignant disease." The following case report is believed to be the first example of cerebellar degeneration in association with carcinoma of the stomach.

\section{CASE REPORT}

A 33-year-old man was admitted to hospital with a history that two weeks previously he had a flu-like illness. For a week he had been complaining of headaches, rambling and slurred speech, and difficulty in controlling his hands and feet. He had apparently been a heavy drinker, but for six months before admission he had been taking Antabuse (disulfiram) and had not been drinking alcohol. On examination he was afebrile and there was no neck stiffness. General examination showed nothing abnormal. There were severe bilateral cerebellar signs but no nystagmus, and there was marked emotional lability and dysarthria.

Investigations. - White cell count $6,500 / \mathrm{cu} . \mathrm{mm}$.; haemoglobin $15.6 \mathrm{~g} . / 100 \mathrm{ml}$. Cerebrospinal fluid: protein $50 \mathrm{mg} . / 100 \mathrm{ml}$. ; 67 white cells/cu. mm. (polymorphs 3\%, lymphocytes $97 \%$ ). Virus studies on blood and cerebrospinal fluid were negative.

- No change occurred in his condition over the next few days and he left hospital against medical advice. A month later he was admitted to another hospital. Examination was as before and the cerebraspinal fluid showed: protein $30 \mathrm{mg} . / 100 \mathrm{ml}$., and 5 white cells per cu. mm., including 4 lymphocytes and 1 mononuclear cell.

He was next seen a year later, when he stated that for the previous three months he had been vomiting after meals and on three

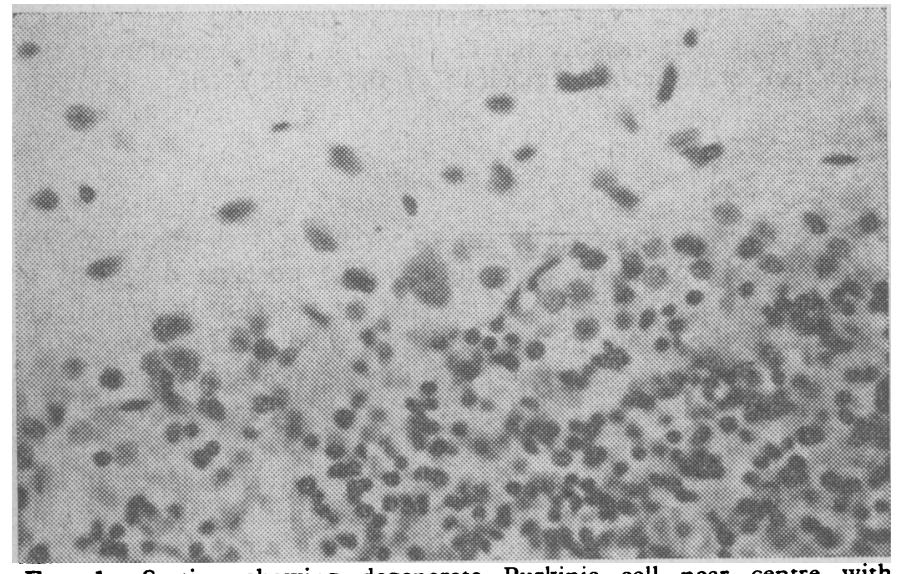

FIG. 1.-Section showing degenerate Purkinje cell near centre with shrinkage and homogenizing changes. (H. and E. $\times 285$.)

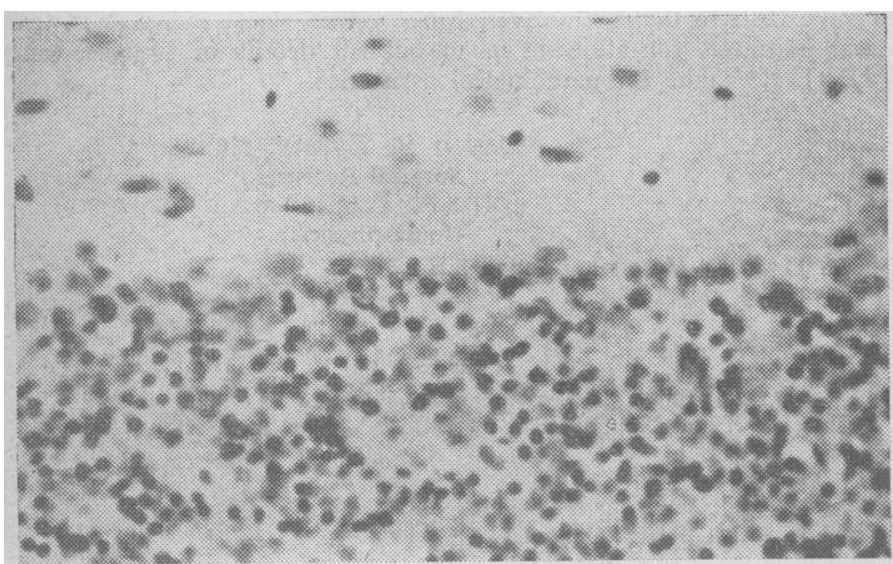

FIG. 2.-Section showing depopulation of granular layer of cerebellar cortex. $(\mathrm{H}$. and E. $\times 285$.) occasions had vomited a cupful of red blood. Examination showed an ill-looking dehydrated man with bilateral cerebellar signs. On abdominal investigation there was a succussion splash but no palpable mass. Barium-meal examination showed a large filling defect on the greater curvature of the stomach with pyloric obstruction. Laparotomy revealed an inoperable carcinoma of the stomach, and gastroenterostomy was performed by Mr. Hamley Wilson. The patient improved for a brief period but died a few weeks later with a recurrence of complete obstruction of the alimentary tract.

Necropsy Findings.-Bronchopneumonic changes were present in both lungs. A tumour mass was filling the antrum of the stomach, infiltrating its wall and the stoma of the gastrojejunostomy, and occluding the pylorus and stoma. There was tumour involvement of the gastric lymph nodes and extensive peritoneal seeding. Microscopy showed the tumour to be an adenocarcinoma.

Central Nervous System.-Macroscopically the cerebellum showed atrophy, and on section the folia were small, yellowish, and friable. The basilar portion of the pons was reduced in size. No tumour tissue was seen within the cranial cavity.

Microscopy.-There was a pronounced generalized reduction in Purkinje cells. The few cells remaining showed degenerative changes (Fig. 1). There was a depopulation of the granular layer of the cerebellar cortex (Fig. 2). The cells in the dentate nuclei showed shrinkage. Diffuse demyelination was noted in the cerebellum, particularly in the peduncles. Slight perivascular cuffing of some vessels of the deeper cerebellar cortex was noted. The cerebral hemispheres were normal.

\section{Discussion}

The clinical course in this patient was consistent with that described by others in cases of cerebellar degeneration in association with carcinoma (Brain, Daniel, and Greenfield, 1951 ; Henson, Russell, and Wilkinson, 1954 ; Brain and Henson, 1958 ; Brain and Wilkinson, 1965a, 1965b). The onset was acute and preceded the discovery of the carcinoma by over 12 months. A severe ataxia of gait and of the limbs with a marked dysarthria were the prominent features, and nystagmus was absent. Apart from marked emotional lability there was no evidence of neurological involvement on clinical grounds.

On pathological examination there was a pronounced loss of Purkinje cells. This was seen throughout the cerebellar hemispheres and vermis. There was also a perivascular lymphocytic infiltration. The distribution of the degenerative process was in accord with that described by others in carcinomatous degeneration (Greenfield, 1954 ; Brain and Wilkinson, 1965a). These pathological findings are in contrast to the rather restricted form of cerebellar cortical degeneration particularly affecting the anterior and superior aspects of the cerebellar hemispheres that is seen in alcoholic patients (Victor, Adams, and Mancall, 1959).

In extensive reviews of the cerebellar degenerations (Victor et al., 1959 ; Brain and Wilkinson, 1965b) no cases were found in association with carcinoma of the stomach. Croft and Wilkinson (1963) recorded a differential incidence of carcinomatous neuromyopathy with various types of carcinoma.

Helpful information about this patient was supplied by Dr. Andrew Skarbek and the Medical Superintendents of Fairfield Hospital, Melbourne, and the Alfred Hospital, Melbourne. Dr. Michael Drake helped with the pathological material.

JOHN I. BALLA, M.R.C.P.ED., M.R.A.C.P., Honorary Assistant Neurologist, Prince Henry's Hospital, Melbourne.

\section{REPERENCES}

Brain, Lord, Daniel, P. M., and Greenfield, J. G. (1951). 7. Neurol Neurosurg. Psychiat., 14, 59. Neurosurg. Psychiat., 14, Lancet, 2, 971. and Henson, R. A. (1958). Lancet, 2, 971. and Wilkinson, M. (1965a). Brain, 88, 465. System, edited by Lord Brain and F. H. Norris, p. 17. New York and London.

Croft, P. B., and Wilkinson, M. (1963). Lancet, 1, 184.

(1965). Brain, 88, 427.

Greenfield, J. G. (1954). S Sino-cerebellar Degenerations, p. 72. Oxford Henson, R. A.. Russell, D. S., and Wilkinson, M. (1954). Brain, 77, 82 Victor, M., Adams, R. D., and Mancall, E. L. (1959). Arch. Neurol 'Chic.), 1, 579 . 